\title{
Risperidone Monotherapy in Children and Adolescents with Autism Spectrum Disorders : A Naturalistic Study
}

\author{
Eun-Kyung Won, M.D. ${ }^{1)^{*}}$, Jin-Park Park, M.D. ${ }^{2 *}$, Young-Ryul Lee, M.D. ${ }^{3)}$, \\ Yoon-Young Nam, M.D., Ph.D. ${ }^{2)}$, He-Ji Min, M.D. ${ }^{4)}$, and Yeni Kim, M.D., Ph.D. ${ }^{1)}$ \\ ${ }^{1)}$ Department of Child Psychiatry, Center for Child and Adolescent Psychiatry, Seoul National Hospital, Seoul, Korea \\ ${ }^{2}$ Division of Planning and Public Relations, Seoul National Hospital, Seoul, Korea \\ ${ }^{3)}$ Center for Child and Adolescent Psychiatry, Seoul National Hospital, Seoul, Korea \\ ${ }^{4)}$ Department of Adolescent Psychiatry, Center for Child and Adolescent Psychiatry, Seoul National Hospital, Seoul, Korea
}

Objectives : We retrospectively investigated the efficacy and tolerability of risperidone monotherapy in subjects with autism spectrum disorder (ASD). In addition, we did mixed effect model analysis of the effects of risperidone in patients with ASDs naturalistically treated in a routine clinical setting to determine whether the clinical effects were maintained and the side effects were tolerable.

Methods : This retrospective study assessed children and adolescents with ASD, who were on risperidone monotherapy from July 2010 to July 2011 at the Child and Adolescent ASD Clinic at Seoul National Hospital. Outcome measures included the Clinical Global Impression-Severity of Illness (CGI-S) and the CGI-Improvement (CGI-I) scales along with other clinical indices: dosage, target symptoms, and side effects.

Results: The mean dose of risperidone in 47 children and adolescents with ASD (40 males, 7 females; age range 5-19 years) who were on risperidone monotherapy was $1.6 \pm 0.8 \mathrm{mg}$ /day, and the mean duration of the treatment period was $20.2 \pm 17.3 \mathrm{months}$. Aggressive behavior, stereotypic behavior, irritability, and self-injurious behavior were the most frequent target symptoms of risperidone. The most common side effects were weight gain followed by somnolence and extrapyramidal symptoms. In a mixed effects model analysis of CGI-I scores, the mean CGI-I score at the 1 month follow-up was significantly different from the mean CGI-I score of the 3-month follow-up ( $\mathrm{p}=.046$ ), and the CGI-I scores were equally maintained over 3 to 48 months [F(6, $28.9)=4.393, \mathrm{p}=.003]$. Of the 47 patients, 33 patients $(70.2 \%)$ were identified as the response group, showing an end point CGI-I rating of 3 or under and having continued risperidone treatment for at least 6 months. The baseline CGI-S score showed significant association with clinical response to risperidone $(\mathrm{p}=.005)$, the mean baseline CGI-S was higher in the response group compared to the non-response group.

Conclusion : In this study, clinical improvement of risperidone stabilized around 3 months and was equally maintained up to 48 months with tolerable side effects, supporting maintenance of risperidone treatment in children and adolescents with ASDs.

KEY WORDS : Adolescents · Autism Spectrum Disorder · Children · Clinical Global Impression · Maintenance · Risperidone.

\section{Introduction}

Autism spectrum disorders (ASDs) are characterized by impaired development of social interactions, communication difficulties, repetitive patterns of movements and behaviors

Date received : August 26, 2015

Date of revision : October 19, 2015

Date accepted : October 21, 2015

Address for correspondence : Yeni Kim, M.D., Ph.D., Department of Child Psychiatry, Center for Child and Adolescent Psychiatry, Seoul National Hospital, 398 Neungdong-ro, Gwangjin-gu, Seoul 04933, Korea

Tel : +82.2-2204-0301, Fax : +82.2-2204-0355

E-mail : yeni1004@gmail.com

*Both authors contributed equally to the manuscript. that include restricted interests and activities. ${ }^{1)}$ Recent estimates of the prevalence of ASDs are in the range of 6.5-6.6 per 1000 individuals, with a male to female ratio of $4: 1{ }^{2,3)}$ The primary treatments for ASDs, including educational interventions, behavioral strategies, and social skills instruction, are used to relieve the core features of ASDs. Despite positive results, several limitations and feasibility issues remain when considering the cost, amount of time required, and practitioner availability required for behavior interventions. Although pharmacotherapy has not been proven to correct the core deficits, it has been used in patients with ASDs. ${ }^{4}$ Behavioral problems, such as aggression, impulsivity, selfinjurious behavior, irritability and hyperactivity, are common 
in individuals with ASDs and are associated with caregiver stress.

The appropriate use of medications in patients with ASDs can improve some maladaptive behaviors and increase patients' abilities to benefit from psychosocial interventions. ${ }^{4}$ The pharmacological approach is primarily aimed at reducing problematic behaviors, such as aggression, self-injurious behavior, stereotypic behavior, and tantrums. ${ }^{5)}$ Low dose antipsychotics have been shown to reduce repetitive behaviors and social withdrawal as well as a number of related symptoms, such as hyperactivity, aggression, self-injurious behavior, labile mood and irritability. ${ }^{6)}$ In October 2006, the Food and Drug Administration approved risperidone for the treatment of maladaptive behaviors in autistic children and adolescents. ${ }^{6}$ Risperidone is the most extensively studied antipsychotic for use in children with ASDs. Most studies were conducted on children and adolescents with maladaptive behaviors. ${ }^{7)}$

In many studies, the efficacy and safety of risperidone treatment has been evaluated. These previous studies showed that risperidone was superior to a placebo in controlling behavioral disturbances in more than half of the participants. ${ }^{8,9)}$ Risperidone has also been associated with adjuvant agents with the aim of treating maladaptive behaviors in autism. ${ }^{10)}$ Pharmacotherapy with a low dose of risperidone in addition to parental training resulted in a greater reduction in maladaptive behaviors. ${ }^{11)}$ Although there is increased use of antipsychotics in child and adolescent group, the randomized controlled trials on the long-term efficacy of antipsychotics on these populations are inherently difficult due to ethical, logistical, economical and epidemiological reasons. The efficacy of risperidone in ASDs has been reported in long-term studies, ${ }^{9,12,13)}$ which divided outcomes into short-term (less than three months) and long term (over three months). But there were several limitations in these studies. The data collection period was a maximum of 8 months and the study group was comparatively small.

In this study, we retrospectively investigated the clinical improvement with risperidone in patients with ASDs naturalistically treated in a routine clinical setting using mixedeffect analysis to determine whether the clinical improvement were maintained and the side effects tolerable.

\section{Methods}

\section{Subjects}

This retrospective study assessed children and adolescents with ASD, who were on risperidone monotherapy from July 2010 to July 2011 in the Child and Adolescent ASD Clinic at Seoul National Hospital. Patients with ages ranging from 5 to 19 years old were included, and total follow-up periods ranged from 1 month to 48 months. All participants were diagnosed with autistic disorder, pervasive developmental disorder not otherwise specified (PDD NOS), or Asperger's disorder according to the criteria in the Diagnostic and Statistical Manual of Mental Disorders, Fourth Edition, Text Revised. ${ }^{1)}$ Diagnoses were based on a clinical interview of the parent and the child by a child and adolescent psychiatrist. The diagnosis was confirmed by another psychiatrist through review of psychiatric records. The clinical variables including medication history, intelligence quotient (IQ), Social Maturity Scale (SMS) and Childhood Autism Rating Scale (CARS) ${ }^{14)}$ scores, were obtained from medical records. The study protocol was approved by the Institutional Review Board at Seoul National Hospital (IRB No. 2011-7).

\section{Measurements}

Previously, it was shown that the Clinical Global Impression (CGI) scale has good psychometric properties for children and adolescents ${ }^{15)}$ and it is one of the most economic tools in assessing clinical change in autism. ${ }^{16)}$ Most clinical drug trials in children with autism have used clinician report of improvement based on the CGI scale. ${ }^{17)}$ We also utilized CGI to evaluate global symptom severity and symptom improvement.

Changes in illness severity were measured using the Clinical Global Impression-Severity of Illness (CGI-S) scale (1= normal, not at all ill; $2=$ borderline ill; $3=$ mildly ill; $4=$ =moderately ill; 5=markedly ill; $6=$ severely ill; and $7=$ among the most extremely ill). CGI-Improvement (CGI-I) scales were used to evaluate target symptom improvement at 1 month, 3 months, 6 months, 12 months, 24 months, 36 months, and 48 months of risperidone treatment $(1=$ very much improved; $2=$ much improved; $3=$ minimally improved; $4=$ no change; $5=$ minimally worse; $6=$ much worse; and $7=$ very much worse). A psychiatrist (Jin-Park Park) conducted the rating of CGIs on all subjects.

The response group was defined by CGI-I scores and treatment duration based on outcome measures used in previous studies. ${ }^{18)}$ The responders were defined by an end point CGI-I rating of 3 or under, and treatment continuation for at least 6 months.

\section{Statistical analysis}

Descriptive analyses were used as appropriate. Independent-sample t-tests and chi-square tests were used to compare demographic and clinical characteristics between response 
and non-response groups. Fisher exact test was used for nonparametric data. A mixed-effects model of repeated measurement was used to compare changes of mean CGI-I scores according to follow-up intervals. We considered $\mathrm{p}<.05$ to be statistically significant. All statistical analyses were performed using SPSS version 18.0 (SPSS Inc., Chicago, IL, USA).

\section{Results}

\section{Clinical characteristics of participants}

Forty seven patients (40 male; 13.6 \pm 3.5 years) were included in the analysis; the patients ranged in age from 5 to 19 years old. The dosage of risperidone ranged from 1-4 mg/ day $(1.6 \pm 0.8 \mathrm{mg} /$ day $)$. The mean duration of the risperidone treatment period was $20.2 \pm 17.3$ months. Forty three $(91.5 \%)$ patients had IQ of blow 70, and the mean IQ of the subjects was $37.7 \pm 11.7$. The mean SMS was $34.3 \pm 19.7$, and the mean CARS was $33.9 \pm 7.0$. Twenty four patients $(51.1 \%)$ were diagnosed with autistic disorder, 23 patients $(48.9 \%)$ were diagnosed with PDD NOS. Aggressive behavior, irritability, impulsivity, and stereotypic behavior were most frequent target symptoms of risperidone. The most common adverse effect of risperidone was weight gain $(10.6 \%)$ followed by somnolence $(6.4 \%)$ (Table 1$)$.

\section{Clinical improvement of risperidone}

In assessing the clinical efficacy of risperidone in 47 children and adolescents with ASD, the mean CGI-I score at the 1-month follow-up was significantly different from the 3month follow-up ( $\mathrm{p}=.046), 6$-month follow-up $(\mathrm{p}=.001), 12$ month follow-up ( $p=.015), 24$-month follow-up ( $p<.001), 36-$ month follow-up $(\mathrm{p}<.001)$, and the 48-month follow-up ( $\mathrm{p}=$ .003) scores. The mean CGI-I score at the 3-month follow-up was significantly different from the 36-month follow-up ( $\mathrm{p}<$ .039) score (Fig. 1).

Of the 47 subjects, 33 children $(70.2 \%)$ were identified as the responders to risperidone, showing an end point CGI-I rating of 3 or under, and having continued treatment for at least 6 months. When we explored the moderators of risperidone response, we found that subjects in the response and non-response groups had comparable demographics and clinical characteristics, e.g., sex, the age at start of medication, target symptom, level of mental retardation, mean CARS score, mean SMS score and dosage of risperidone (Table 2). However, the baseline CGI-S score was significantly associated with clinical response to risperidone $(p=.005)$. There was no significant difference between the percentage of patients reporting side effects in both response and non-re-
Table 1. Clinical characteristics of children and adolescents treated with risperidone

\begin{tabular}{|c|c|}
\hline & Participants $(\mathrm{N}=47)$ \\
\hline \multicolumn{2}{|l|}{ Sex, N (\%) } \\
\hline Male & $40(85.1)$ \\
\hline Female & $7(14.9)$ \\
\hline Age, years, mean (SD), range & $13.6(3.5), 5-19$ \\
\hline \multicolumn{2}{|l|}{ Diagnosis, N (\%) } \\
\hline Autism & $24(51.1)$ \\
\hline PDD NOS & $23(48.9)$ \\
\hline Mental retardation & $43(91.5)$ \\
\hline \multicolumn{2}{|l|}{ Comorbidity, N (\%) } \\
\hline ADHD & $4(8.5)$ \\
\hline Tic disorder & $3(6.4)$ \\
\hline Epilepsy & $1(2.1)$ \\
\hline Baseline CGI-S score, mean (SD) & $5.2(0.7)$ \\
\hline $\begin{array}{l}\text { Age at start of any medication, years, } \\
\text { mean (SD), range }\end{array}$ & $7.1(4.9), 1-18$ \\
\hline $\begin{array}{l}\text { Dosage of risperidone, mg/day, } \\
\text { mean (SD), range }\end{array}$ & $1.6(0.8), 1-4$ \\
\hline $\begin{array}{l}\text { Duration of risperidone, months, } \\
\text { mean (SD), range }\end{array}$ & $20.2(17.3), 1-48$ \\
\hline 1-3 months, N (\%) & $4(8.5)$ \\
\hline 3-6 months, $\mathrm{N}(\%)$ & $7(14.9)$ \\
\hline 6-12 months, N (\%) & $4(8.5)$ \\
\hline 12-24 months, $\mathrm{N}(\%)$ & $13(26.7)$ \\
\hline $24-36$ months, $\mathrm{N}(\%)$ & $4(8.5)$ \\
\hline 36-48 months, N (\%) & $15(31.9)$ \\
\hline \multicolumn{2}{|l|}{ Adverse effect of risperidone, N (\%) } \\
\hline Weight gain & $5(10.6)$ \\
\hline Somnolence & $3(6.4)$ \\
\hline Extrapyramidal symptoms & $3(6.4)$ \\
\hline Galactorrhea & $1(2.1)$ \\
\hline Amenorrhea & $1(14.3)^{*}$ \\
\hline
\end{tabular}

*: amenorrhea was observed in one subject out of seven female subjects resulting in 14.3\%. CGI-S : Clinical Global Impression-Severity, PDD NOS : pervasive developmental disorder not otherwise specified, SD : standard deviation, ADHD : attentiondeficit hyperactivity disorder

sponse groups.

\section{Discussion}

In this study, we observed the clinical improvement of risperidone monotherapy in 47 children and adolescents with ASD (40 males, 7 females; age range 5-19 years). We found that the mean CGI-I score at 3 months was significantly different compared to the 1 month follow up, and the CGI-I score was equally maintained over 3 to 48 months, supporting the long-term use of risperidone beyond 6 months. Moreover, the mean duration of the treatment period for total subjects was 20 months and for response group was 27 months. Our 
findings suggest that the continued use of risperidone brings about significant improvement in the disruptive behavioral symptoms of ASDs and that the clinical improvement after risperidone stabilizes around 3 months and is maintained till 48 months supporting the long-term use of risperidone be-

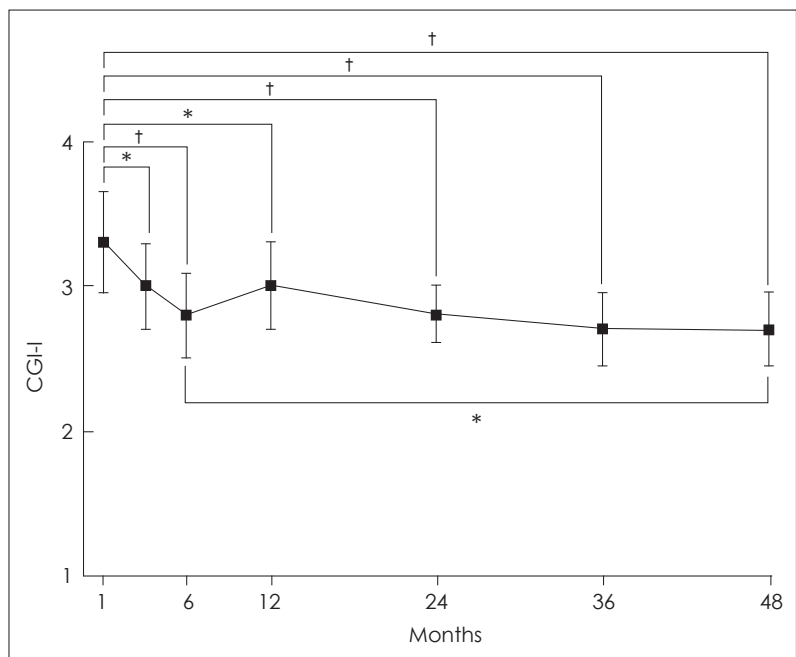

Fig. 1. The clinical improvement of the patients on risperidone stabilizes at 3 months follow-up and is maintained up to 48 month follow-up. The mean CGI-I score at the 1 month followup was significantly different from the mean CGI-I scores of the 3 month follow-up $(p=.046), 6$ month follow-up $(p=.001), 12$ month follow-up $(p=.015), 24$ month follow-up $(p<.001), 36$ month follow-up $(\mathrm{p}<.001)$, and the 48 month follow-up [F(6, 28.9) $=4.393, p=.003]$. The mean CGI-I score at the 3 month follow-up was significantly different from those of the 36 month follow-up ( $p=.039) . *: p<.05,{ }^{\dagger}: p<.005$. CGI-I : Global ImpressionSeverity-Improvement yond 6 months. In a similar note, a previous multisite study of risperidone in children aged 5 to 17 years, the discontinuation after 6 months was associated with a rapid return of disruptive behavior in most subjects. ${ }^{13)}$

Our exploration of moderators of risperidone response in children with ASDs showed that the baseline CGI-S score was significantly associated with clinical response to risperidone $(\mathrm{p}=.005)$ and that the mean baseline CGI-S being higher in the response group compared to the non-response group. These results are similar to previous findings, which showed that a high score in the initial Aberrant Behavior Checklist Irritability subscale was a significant moderator of response rate for risperidone. ${ }^{19)}$

In this study, 33 out of 47 patients $(70.2 \%)$ were identified as the response group, showing end point CGI-I rating of 3 or under and having continued risperidone treatment for at least 6 months. The $70.2 \%$ response rate of risperidone in this study, was similar to previous clinical trials of risperidone in children and adolescents with autism which reported 64$69 \%$ response rate to risperidone in ASDs. ${ }^{9,17)}$ A multisite, double-blind, placebo-controlled trials in children and adolescents with autism revealed a $69 \%$ response rate with a $57 \%$ decrease in irritability as measured by the Aberrant Behavior Checklist (ABC) irritability subscale. ${ }^{20)}$ In another randomized study of 79 children with PDD, risperidone-treated subjects exhibited a $64 \%$ improvement in irritability as measured by the ABC irritability subscale."

Table 2. Clinical characteristics of the responders and non-responders according to CGI-I scores

\begin{tabular}{|c|c|c|c|}
\hline & Response $(\mathrm{N}=33)$ & Non-response $(\mathrm{N}=14)$ & $\mathrm{p}^{*}$ \\
\hline Gender, N (\%) & & & .658 \\
\hline Male & $28(84.8)$ & $12(85.7)$ & \\
\hline Female & $5(15.2)$ & $2(14.3)$ & \\
\hline Age, years, mean (SD) & $13.2(3.7)$ & $14.7(2.7)$ & .115 \\
\hline Target symptom, N (\%) & & & .616 \\
\hline Aggression & $12(36.4)$ & $4(28.6)$ & \\
\hline Irritability & $9(27.3)$ & $2(14.3)$ & \\
\hline Impulsivity & $6(18.2)$ & $4(28.6)$ & \\
\hline Stereotypies & $6(18.2)$ & $4(28.6)$ & \\
\hline Level of mental retardation, N (\%) & & & .658 \\
\hline Mild to moderate & $3(9.1)$ & $1(7.1)$ & \\
\hline Severe to profound & $30(90.9)$ & $13(92.9)$ & \\
\hline SMS, mean (SD) & $34.0(19.1)$ & $35.1(22.7)$ & .909 \\
\hline CARS, mean (SD) & $33.2(5.1)$ & $35.8(10.6)$ & .519 \\
\hline Baseline CGI-S, mean (SD) & $5.0(0.7)$ & $5.6(0.5)$ & .005 \\
\hline Dosage of risperidone, mg/day, mean (SD) & $1.7(0.9)$ & $1.5(0.6)$ & .316 \\
\hline Duration of risperidone, months, mean (SD) & $27.1(16.1)$ & $3.9(3.7)$ & $<.001$ \\
\hline Side effects, N (\%) & $9(27.3)$ & $4(28.6)$ & .596 \\
\hline
\end{tabular}

* : comparisons were performed using t-tests and the Fisher exact test. CARS : Childhood Autism Rating Scale, CGI-I : Clinical Global Impression-Improvement, CGI-S : Clinical Global Impression-Severity, SD : standard deviation, SMS : Social Maturity Scale 
In this study, the mean dose of risperidone was $1.6 \pm 0.8$ $\mathrm{mg} /$ day. Dosages in the previous controlled studies of risperidone ranged from 0.5 to $3.5 \mathrm{mg} / \mathrm{day}$, with the combination of risperidone and parent management training group requiring a lower mean dose compared with the risperidone monotherapy group $(1.98 \mathrm{mg} /$ day versus $2.26 \mathrm{mg}$ /day, respectively). ${ }^{21)}$ The mean dosage of risperidone in our study, 1.6 $\mathrm{mg} /$ day is consistent with previous results.

The most common side effects were weight gain followed by somnolence and extrapyramidal symptoms in this study. But, there was no significant difference in the percentage of subjects reporting side effects in both the response and nonresponse groups of risperidone. As with previous findings, weight gain was the most commonly reported adverse effect in our study. ${ }^{13)}$ According to a naturalistic study of 23 subjects with pervasive developmental disorders, some improvement in the safety and tolerability issues, such as weight gain and somnolence, occurred after switching to aripiprazole. ${ }^{16)}$ Our finding is also consistent with the results from a 6-month prospective study examining 63 children and adolescents with ASD, which reported weight gain in excess of developmentally expected norms. ${ }^{22)}$

There are several limitations in this study, including the fact that it is a naturalisitc study without placebo control group. A retrospective chart review was conducted without systematic clinical data collection; thus, there was no randomization, and the duration of treatment was highly variable. Furthermore, more than $85 \%$ of patients were male, making the findings potentially less generalizable to females. When we assessed the tolerability of risperidone in this study, there was no information on heights and weights at the initiation of risperidone in some subjects. Thus, we could not evaluate the mean weight gain and body mass index score from this study.

Despite the limitations discussed above, a total of 47 patients in Korean population were included in the study, and the mean duration of risperidone monotherapy was long enough to assess the clinical improvement of risperidone for as long as 48 months. Future treatment studies in ASDs need to focus on the frequency and titration of prescribing risperidone and the discontinuation rate due to side effects. Studies are also needed to compare risperidone with other antipsychotics e.g., aripiprazole, which is one of the first agents for the treatment of severe irritability associated with ASD.

\section{Conclusion}

In this study, clinical improvement of risperidone stabi- lized around 3 months and was equally maintained up to 48 months with tolerable side effects, supporting maintenance of risperidone treatment in children and adolescents with ASDs.

\section{References}

1) American Psychiatric Association. Diagnostic and Statistical Manual of Mental Disorders: DSM-4-TR. 4th ed., text revision. Washington, DC: American Psychiatric Association;2000.

2) Autism and Developmental Disabilities Monitoring Network Surveillance Year 2008 Principal Investigators; Centers for Disease Control and Prevention. Prevalence of autism spectrum disorders-Autism and Developmental Disabilities Monitoring Network, 14 sites, United States, 2008. MMWR Surveill Summ 2012;61:1-19.

3) Fombonne E. Epidemiology of pervasive developmental disorders. Pediatr Res 2009;65:591-598.

4) Canitano R, Scandurra V. Psychopharmacology in autism: an update. Prog Neuropsychopharmacol Biol Psychiatry 2011;35:18-28.

5) McDougle CJ, Stigler KA, Erickson CA, Posey DJ. Atypical antipsychotics in children and adolescents with autistic and other pervasive developmental disorders. J Clin Psychiatry 2008;69 Suppl 4: $15-20$.

6) Malone RP, Waheed A. The role of antipsychotics in the management of behavioural symptoms in children and adolescents with autism. Drugs 2009;69:535-548.

7) Canitano R, Scandurra V. Risperidone in the treatment of behavioral disorders associated with autism in children and adolescents. Neuropsychiatr Dis Treat 2008;4:723-730.

8) Pandina GJ, Bossie CA, Youssef E, Zhu Y, Dunbar F. Risperidone improves behavioral symptoms in children with autism in a randomized, double-blind, placebo-controlled trial. J Autism Dev Disord 2007;37:367-373.

9) Shea S, Turgay A, Carroll A, Schulz M, Orlik H, Smith I, et al. Risperidone in the treatment of disruptive behavioral symptoms in children with autistic and other pervasive developmental disorders. Pediatrics 2004;114:e634-e641.

10) Akhondzadeh S, Fallah J, Mohammadi MR, Imani R, Mohammadi M, Salehi B, et al. Double-blind placebo-controlled trial of pentoxifylline added to risperidone: effects on aberrant behavior in children with autism. Prog Neuropsychopharmacol Biol Psychiatry 2010;34:32-36.

11) Aman MG, McDougle CJ, Scahill L, Handen B, Arnold LE, Johnson C, et al. Medication and parent training in children with pervasive developmental disorders and serious behavior problems: results from a randomized clinical trial. J Am Acad Child Adolesc Psychiatry 2009;48:1143-1154.

12) Troost PW, Lahuis BE, Steenhuis MP, Ketelaars CE, Buitelaar JK, van Engeland H, et al. Long-term effects of risperidone in children with autism spectrum disorders: a placebo discontinuation study. J Am Acad Child Adolesc Psychiatry 2005;44:1137-1144.

13) Research Units on Pediatric Psychopharmacology Autism Network. Risperidone treatment of autistic disorder: longer-term benefits and blinded discontinuation after 6 months. Am J Psychiatry 2005;162:1361-1369.

14) Schopler E, Reichler RJ, DeVellis RF, Daly K. Toward objective classification of childhood autism: Childhood Autism Rating Scale (CARS). J Autism Dev Disord 1980;10:91-103.

15) Guy W. ECDEU assessment manual for psychopharmacology revised. Rockville, MD: US Department of Health, Education, and Welfare Public Health Service Alcohol, Drug Abuse, and Mental Health Administration;1976.

16) Choque Olsson N, Bölte S. Brief report: "Quick and (not so) dirty" assessment of change in autism: cross-cultural reliability of the De- 
velopmental Disabilities CGAS and the OSU autism CGI. J Autism Dev Disord 2014;44:1773-1778.

17) Memarzia J, Tracy D, Giaroli G. The use of antipsychotics in preschoolers: a veto or a sensible last option? J Psychopharmacol 2014; 28:303-319.

18) Lemmon ME, Gregas M, Jeste SS. Risperidone use in autism spectrum disorders: a retrospective review of a clinic-referred patient population. J Child Neurol 2011;26:428-432.

19) Arnold LE, Farmer C, Kraemer HC, Davies M, Witwer A, Chuang $\mathrm{S}$, et al. Moderators, mediators, and other predictors of risperidone response in children with autistic disorder and irritability. J Child
Adolesc Psychopharmacol 2010;20:83-93.

20) McCracken JT, McGough J, Shah B, Cronin P, Hong D, Aman MG, et al. Risperidone in children with autism and serious behavioral problems. N Engl J Med 2002;347:314-321.

21) Doyle CA, McDougle CJ. Pharmacologic treatments for the behavioral symptoms associated with autism spectrum disorders across the lifespan. Dialogues Clin Neurosci 2012;14:263-279.

22) Martin A, Scahill L, Anderson GM, Aman M, Arnold LE, McCracken J, et al. Weight and leptin changes among risperidonetreated youths with autism: 6-month prospective data. Am J Psychiatry 2004;161:1125-1127. 